\author{
반탄화를 이용한 하수슬러지 연료화에 관한 연구 \\ 이윤경 · 김재형 · 강설송 · 김경아 · 박대원 ${ }^{\dagger}$ \\ 서울과학기술대학교 에너지환경대학원 에너지환경공학과 \\ (2013년 10월 5일 접수, 2013년 12월 10일 수정, 2013년 12월 10일 채택)
}

\title{
A study on the fuel of sewage sludge by torrefaction process
}

\author{
Lee yoonkyung $\cdot$ Pak Daewon ${ }^{\dagger}$
}

Graduate School of energy and Environment, Seoul National University of Technology \& Science,

(Received 5 October 2013, Revised 10 December 2013, Accepted 10 December 2013)

요 약

본 연구에서는 하수슬러지를 이용하여 높은 에너지 밀도와 균일한 품질의 고형연료 생산을 위해 반탄 화 기술을 적용하여 반탄화 생성물의 특성과 에너지원으로서의 가치를 확인하였다. 운전인자로 반응온 도 $\left(150-230^{\circ} \mathrm{C}\right)$ 와 반응시간(10-60분)을 달리한 결과, 반응온도가 높고, 반응시간이 길어질수록 반탄화 생성물의 수분함량은 감소하고, 발열량은 증가하였다. 또한 반응온도 조건의 상승과 함께 탄소의 함량 이 초기 시료(하수슬러지 탈수케이크) 대비 최대 $60 \%$ 까지 증가하였고, 산소와 수소의 함량은 감소하는 경향을 나타내었다. 특히 반응온도 $210^{\circ} \mathrm{C}$ 이상에서는 반응시간에 관계없이 평균 발열량 약 4,818 $\mathrm{kcal} / \mathrm{kg}$ 를 나타내었으며, 연료비, 석탄밴드 분석 결과 $\mathrm{H} / \mathrm{C}$ 와 $\mathrm{O} / \mathrm{C}$ 의 원자수비가 낮아져 반탄화를 통해 저등급 석탄에 가까운 연료등급으로 개선되었음을 확인 할 수 있었다.

주요어 : 반탄화, 하수슬러지, 고형연료, 발열량, 에너지 밀도, 연료비, 석탄밴드

Abstract - In this work, torrefaction of the sewage sludge was investigated the characteristics of torrefied products and the value of as energy resource to improve energy density and to maintain consistent quality of SRF. Torrefaction was performed two important torrefaction operational parameter, temperature $\left(150-230^{\circ} \mathrm{C}\right)$ and reaction time(10-60min). As raising the torrefaction temperature at long reaction times, the moisture content of torrefied products was decreased, while the heating value was increased. Moreover, increasing of the torrefaction temperature led to a increase of the content of the carbon up to $60 \%$ compare to the initial the sample, and a decrease of the content hydrogen and oxygen. Especially, Average heating value was 4,818 $\mathrm{kcal} / \mathrm{kg}$ regardless of the reaction time when torrefaction was performed over $210^{\circ} \mathrm{C}$. In addition, the fuel ration and coal band were improved after torrefaction because the $\mathrm{O} / \mathrm{C}$ and the $\mathrm{H} / \mathrm{C}$ ratio were decreased.

Key words : Torrefaction, Sewage sludge, SRF(Solid Refuse Fuel), Heating value, Energy density, Fuel ratio, Coal band

\section{1. 서 론}

\section{최근 전 세계 인구증가 및 신흥경제국의 경제 발전}

\footnotetext{
${ }^{\dagger}$ To whom corresponding should be addressed.

Department of Environmental Energy Engineering, Graduate School of energy and Environment, Seoul National University of Technology \& Science, Seoul 139-743, Korea

Tel : 02-970-6595 E-mail : daewon@seoultech.ac.kr
}

에 따른 에너지 수요 급증으로 인하여 석유를 포함한 화석연료의 소비량은 계속적으로 증가하고 있으나, 아직 화석연료를 대체할 수 있는 확실한 다른 에너지 원의 개발은 미흡한 실정이다. 일본 후쿠시마 원전 사태 이후, 에너지원의 많은 부분을 생산하고 있는 원자력발전소는 안전성과 수명 연장 등의 여러 가지 문제들로 증설 계획을 연기 또는 폐지시켰으며, 이로 
인한 화석에너지의 수요 증가 및 고유가 정책으로 화 석연료의 가격 상승 추세는 앞으로도 계속 될 전망이 다. 각국은 이와 같은 문제들을 해결하고 지구 온난 화 현상의 방지책의 일환으로 신·재생에너지의 개발 에 힘쓰고 있으며, 그 중 폐기물에너지화의 중요성을 크게 강조하고 있다. 다른 신·재생에너지에 비해 단 기간 내에 상용화 및 대량보급이 가능한 분야로, 국 내의 경우 2008년 폐기물에너지화 종합대책과 2009 년 폐자원 및 바이오매스 에너지 대책의 실행계획을 수립하여, 2013년까지 국가 신·재생에너지 보급 목표 율 $3.78 \%$ 중 폐기물 및 바이오매스 분야에 $83.9 \%$ 에 해당하는 $3.17 \%$ 를 할당하였으며(1), 특히 하수슬러지 를 포함한 유기성폐기물의 경우 런던협약 ' 96 의정서' 발효와 함께 해양투기가 전면 금지됨에 따라 이를 자 원으로 전환하여 재활용하기 위한 연구가 활발히 진 행되고 있다. 하수슬러지를 재활용하는 방법은 복토 재, 시멘트원료, 녹생토, 퇴비화, 탄화, 고형연료화 등 이 있다. 이 중 하수슬러지의 연료화 기술은 슬러지 가 가지고 있는 열량을 연료로 이용할 수 있는 수준 까지 높여 기존 화석 연료와 유사한 형태로 만드는 기술로 석탄의 대체 연료로 활용이 가능하므로 연료 수입 대체 효과를 기대할 수 있지만, 생산된 연료의 균일한 품질보장과 수요처의 상황, 열량을 높이기 위 해 투입하는 첨가제의 수급상황 등 아직 기술에 대한 신뢰성과 안정성이 미흡한 실정이다.(2)

반탄화는 열적 전처리 방법 중의 하나로 목질계 바 이오매스가 가지고 있는 낮은 발열량, 높은 함수율 등의 문제와 더불어 탄화에서 발생하는 높은 원료의 손실을 개선시키기 위해 연구되어 왔다. 일반적으로 무산소 또는 저산소 상태에서 비교적 낮은 온도인 $200-300^{\circ} \mathrm{C}$ 에서 1 시간 이내로 열처리를 수행하여 바이오매스에 존재하는 수분과 휘발성 물질을 제거한 다. 반탄화 생성물은 처리 전에 비해 발열량이 증가 하는 한편 함수율이 낮아지게 되며, 바이오매스 내에 존재하는 수산기가 제거되어 소수성이 증가하여 장기 간의 보관이 용이하다. 또한 중량 감소에 비해 바이 오매스의 에너지 손실이 적게 일어나 에너지밀도를 향상 시킬 수 있어 수용비용을 절감할 수 있다.(3-5) 그러나 현재까지 유기성폐기물에 본 기술이 적용된 사례는 극히 드물어 운전조건 인자에 따른 체계적인 연구가 필요하다. 이에 본 연구에서는 하수슬러지 탈 수케이크를 이용하여 실험실 규모의 회분식 반응기에 서 반응온도와 반응시간의 변화에 따른 반탄화 생성
Table 1. Characteristics of sewage sludge

\begin{tabular}{|c|c|c|c|}
\hline \multicolumn{2}{|r|}{ Item } & Unit & sewage \\
\hline \multirow{4}{*}{$\begin{array}{c}\text { Proximate } \\
\text { analysis }\end{array}$} & Moisture & \multirow{5}{*}{ wt $\%$} & 80.5 \\
\hline & Volatile matter & & 7.0 \\
\hline & Fixed carbon & & 4.9 \\
\hline & Ash & & 7.6 \\
\hline \multirow{5}{*}{$\begin{array}{c}\text { Elemental } \\
\text { analysis }\end{array}$} & $\mathrm{C}$ & & 30.1 \\
\hline & $\mathrm{H}$ & \multirow{5}{*}{4.2} & \\
\hline & $\mathrm{O}$ & & 21.3 \\
\hline & $\mathrm{N}$ & & 4.0 \\
\hline & $\mathrm{S}$ & & 1.6 \\
\hline \multicolumn{2}{|c|}{ Heating value } & & $\mathrm{kcal} / \mathrm{kg}$ \\
\hline
\end{tabular}

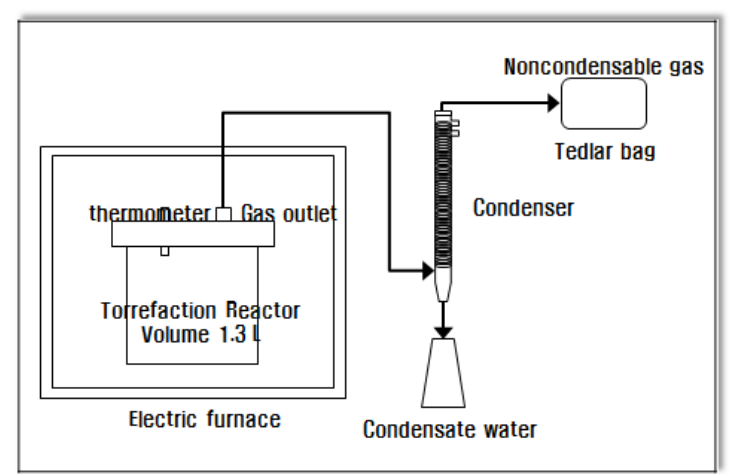

Fig. 1. Schematic diagram of lab-scale torrefaction reactor

물의 물리·화학적 특성 그리고 연료적 특성을 파악하 여 에너지원으로서의 가치를 평가하고자 하였다.

\section{2. 실험재료 및 방법}

\section{1 실험재료}

실험에 사용한 시료는 서울특별시 소재 $\mathrm{J}$ 물재생센 터의 혐기성 소화슬러지의 탈수케이크를 대상으로 하 였으며, 본교 교내식당의 폐유를 열매체유로 사용하 였다. 하수슬러지 탈수케이크의 물리·화학적 특성을 Table 1에 나타내었다. 수분함량, 휘발분, 고정탄소 및 회분은 각각 $80.5 \%, 7.0 \%, 4.9 \%$ 및 $7.6 \%$ 이었으 며, 원소분석 결과 탄소 $30.1 \%$, 산소 $21.3 \%$ 로 유기 화합물의 대부분을 차지하였으며, 황의 함량은 비교 적 낮았다. 


\section{2 실험장치}

본 실험에 사용된 실험실 규모의 회분식 반탄화 장 치는 Fig. 1과 같다. 실험 장치는 전기로(Electronic furnace), 반응기(Reactor), 응축기(Condenser)로 구 성되어 있으며, 반응기는 스테인리스강(Stainless steel) 재질로 유효용적은 $1.3 \mathrm{~L}$ 이고, 반응기의 완전 밀폐를 위하여 테프론(Teflon)소재의 가스켓을 이용 하였으며, 실제 온도와 설정 온도의 오차 범위를 최 소한으로 줄이기 위하여 온도 조절 제어장치가 장착 된 전기로를 사용하였다.

\section{3 반탄화 공정}

본 연구에서는 일정한 승온속도와 시료량의 조건 에서 반응온도와 반응시간을 변화시켜 각각의 운전조 건에 따른 반탄화 생성물의 특성 및 연료적 특성을 살펴보았다. 반응온도는 설정온도의 $\pm 10^{\circ} \mathrm{C}$ 범위로 조절하였으며, 이 온도에서의 체류시간을 반응시간으 로 설정하였다. 실험은 상온에서 하수슬러지 탈수케 이크 $100 \mathrm{~g}$ 과 열매체유 $300 \mathrm{~mL}$ 를 반응기에 혼합하여 넣은 후, 질소 가스를 이용하여 반응기 내부를 질소 분위기로 치환하였다. 반응기 온도는 전기로를 사용 하여 승온속도 $10^{\circ} \mathrm{C} / \mathrm{min}$ 으로 온도를 조절하였고, 최 종 온도에서 반응시간 동안 유지한 후 실험을 종료하 였다. 실험 종료 후 반응기를 상온에서 냉각시켰으며, 채취된 시료는 원심분리기(2,500rpm, 10 분)를 이용하 여 생성물과 열매체유를 분리하였다.

반탄화 최종 생산물은 원소분석기(Vario MACRO, Elementar, German)와 발열량계(Leco AC 500)를 이 용하여 정량.정성 원소분석과 발열량을 확인하였고, 공업분석은 ASTM D3172, D3174, D3175에 의해 4 성분(고정탄소, 휘발분, 수분, 회분)을 확인하였다. 계 산식 (1)를 통해 차(char)의 고정탄소 수율을 구하고 연료비와 석탄밴드를 통해 연료적 특성을 평가하였 다.

$$
\text { FCchar }=\text { Mchar } \times[\mathrm{fc} /(100-\mathrm{fa})]
$$

여기서, Mchar 는 생성된 차(char)의 물질수율, $\mathrm{fc}$ 는 생성된 차(char)의 고정탄소(\%), fa는 초기 시료의 회분(\%)이다.

\section{3. 결과 및 고찰}

3.1. 운전조건에 따른 반탄화 생성물의 특성

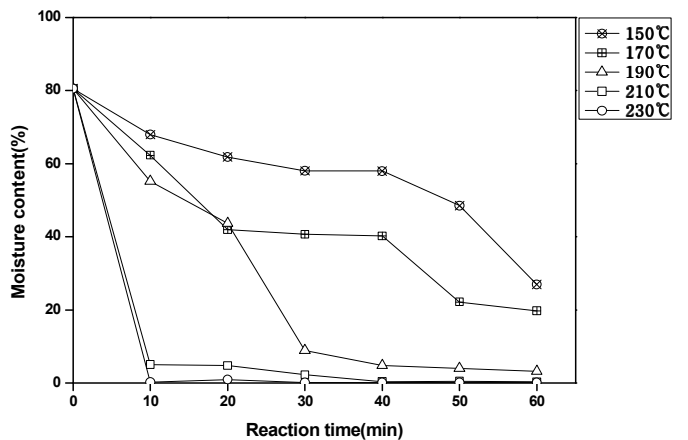

Fig. 2. Moisture content of torrefied products by different temperature and reaction time

Fig. 2에는 다양한 반응온도(150, 170, 190, 210, $\left.230{ }^{\circ} \mathrm{C}\right)$ 와 반응시간 $(10$ - 60 분)에 따른 반탄화 생성 물인 차(char)의 수분함량 변화를 나타내었다. 수분함 량이 $80 \%$ 인 탈수케이크는 반응온도가 높고 반응시간 이 길어질수록 반탄화 생성물의 수분 감소가 큰 것으 로 나타났으며, 특히 반응온도 $210^{\circ} \mathrm{C}$ 이상에서는 급 격한 수분 감소를 보이고 있으며 반응시간에 관계없 이 유사한 경향을 나타내었다. 이는 탈수케이크가 포 함하고 있는 수분이 증발되어 가스로 발생하기 때문 이다. 슬러지가 포함하고 있는 수분은 슬러지 표면과 내부로 위치가 구분되며 대부분의 수분은 슬러지 내 부의 간극수와 미생물이 포함하고 있는 결합수의 형 태로 존재하는 것으로 알려져 있다. 이로 인해 수분 이 기화되는 온도인 $100^{\circ} \mathrm{C}$ 에서는 슬러지 표면에 존 재하는 미량의 자유수가 증발되어 수분 감소가 크게 나타나지 않으나, 온도가 상승함에 따라 슬러지 표면 에 크랙이 형성되어 내부에 존재하는 수분이 외부로 빠져나와 높은 수분 감소를 나타내게 되며(6), 본 연 구결과에서도 이와 유사하게 반응온도가 높을수록 낮 은 수분함량을 나타낸 것으로 판단된다. 특히 , Fenfen $\mathrm{Zhu}$ (7) 등의 연구결과에 의하면 슬러지의 상 태와 온도별 건조효율 결과를 통해 $200^{\circ} \mathrm{C}$ 기준에서 처리 시 수분함량의 감소변화가 가장 크게 이루어진 것으로 보고된 바 있으며 본 연구결과에서도 이와 유 사한 $210^{\circ} \mathrm{C}$ 에서 가장 높은 수분함량의 감소를 보였 다. 이를 통해 반탄화의 가장 중요한 운전조건은 반 응온도이며, 하수슬러지 탈수케이크의 열적 특성을 고려하면서 선정되어야 함을 알 수 있었다.

Fig. 3에는 반응온도 및 반응시간에 따른 반탄화 생성물의 발열량 변화를 나타내었다. 반응온도가 상 


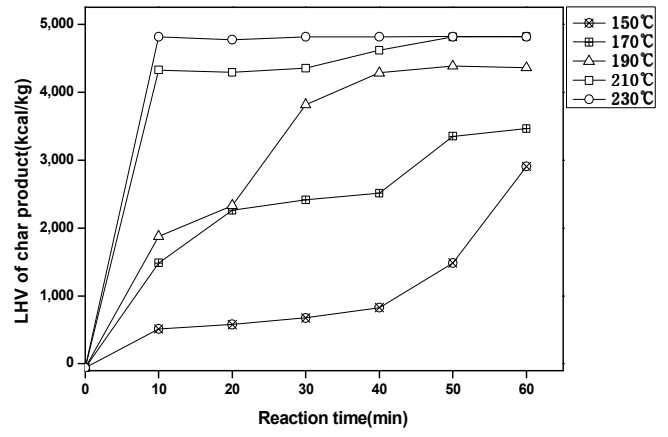

Fig. 3. The heating value of torrefied products by different temperature and reaction time

승함에 따라 봄베열량계 측정값은 증가하는 경향을 나타내었고, 반응온도 $210^{\circ} \mathrm{C}$ 이상에서는 반응시간에 관계없이 $4,000 \mathrm{kcal} / \mathrm{kg}$ 이상의 값을 나타내었다. 이 는 반응온도 상승과 함께 수분함량이 감소하면서 상 대적으로 탄소가 고정되기 때문이며, 일정 온도 이상 에서는 더 이상의 수분함량 및 휘발성분이 제거 되지 않기 때문인 것으로 보여 진다. $(8,9)$ 반탄화 처리 전 탈수케이크의 발열량은 $638 \mathrm{kcal} / \mathrm{kg}$ 로 이를 직접 연 료로 사용하기에는 적합하지 않으나, 반탄화 처리 후 $3,000 \mathrm{kcal} / \mathrm{kg}$ 이상의 발열량을 보였다. 이는 『폐기물 관리법』 제 2조 제 4 호의 고형연료제품(SRF) 기준인 $3,500 \mathrm{kcal} / \mathrm{kg}$ 에 만족하였으며, 비교적 낮은 온도에서 의 반탄화 처리로도 발열량이 크게 증가하는 이유는 수분의 증발이 큰 비중을 차지하기 때문인 것으로 보 여 진다.

\section{2 반탄화 생성물의 기초 특성}

반탄화 온도별 생성물인 차(char)에 대한 기초물 성인 공업분석과 원소분석 결과를 Table 2, Table 3 에 나타내었다. Table 2에 나타낸 바와 같이 반탄화 처리 전의 탈수케이크는 수분함량 $80 \%$ 로 측정되었 다. 하지만 반탄화가 진행됨에 따라 수분함량이 $1 \%$ 미만으로 감소하는 것을 확인 할 수 있었다. 또한 반 탄화 온도가 증가함에 따라 고정탄소는 증가하고 회 분은 증가하는 추세를 보였다. 고정탄소의 증가는 앞 서 진술한 발열량과 깊은 관련이 있으며, 회분의 증 가는 반탄화가 진행될수록 대부분의 수분 감소로 인 해 상대적으로 무기물 즉 회분의 비율이 높아진 것으 로 보여 진다.(10-12) 회분은 발열량을 높이는 요소는
Table 2. Proximate analysis of torrefied product at different torrefaction temperatures (Reaction time $=60 \mathrm{~min}$ )

\begin{tabular}{c|c|c|c|c}
\hline Sample & $\begin{array}{c}\text { Moisture } \\
(\%)\end{array}$ & $\begin{array}{c}\text { Volatile } \\
\text { matter(\%) }\end{array}$ & $\begin{array}{c}\text { Fixed } \\
\text { carbon(\%) }\end{array}$ & $\begin{array}{c}\text { Ash } \\
(\%)\end{array}$ \\
\hline \hline $150^{\circ} \mathrm{C}$ & 27.0 & 22.3 & 30.7 & 20.0 \\
\hline $170^{\circ} \mathrm{C}$ & 19.8 & 23.6 & 31.2 & 25.4 \\
\hline $190^{\circ} \mathrm{C}$ & 4.9 & 28.3 & 37.6 & 29.2 \\
\hline $210^{\circ} \mathrm{C}$ & 0.9 & 29.3 & 44.5 & 25.3 \\
\hline $230^{\circ} \mathrm{C}$ & 0.4 & 29.3 & 44.5 & 25.8 \\
\hline
\end{tabular}

Table 3. Proximate analysis of torrefied product at different torrefaction temperatures (Reaction time $=60 \mathrm{~min}$ )

\begin{tabular}{c|c|c|c|c|c}
\hline Sample & $\mathrm{C}(\%)$ & $\mathrm{H}(\%)$ & $\mathrm{O}(\%)$ & $\mathrm{N}(\%)$ & $\mathrm{S}(\%)$ \\
\hline \hline $150^{\circ} \mathrm{C}$ & 38.6 & 5.4 & 18.9 & 3.1 & 1.6 \\
\hline $170^{\circ} \mathrm{C}$ & 40.2 & 5.4 & 18.7 & 3.0 & 1.2 \\
\hline $190^{\circ} \mathrm{C}$ & 41.8 & 5.3 & 18.1 & 2.9 & 1.1 \\
\hline $210^{\circ} \mathrm{C}$ & 43.5 & 5.3 & 16.7 & 2.8 & 1.1 \\
\hline $230^{\circ} \mathrm{C}$ & 48.5 & 5.1 & 16.8 & 2.5 & 1.1 \\
\hline
\end{tabular}

아니며, 회분함량이 적을수록 높은 발열량을 얻는 데 유리한 것으로 판단된다. 휘발분의 경우 반탄화 온도 가 높아짐에 따라 그 비율이 상승하였다가 $190^{\circ} \mathrm{C}$ 이 상에서는 변화가 없음을 알 수 있었다. 이는 $190^{\circ} \mathrm{C}$ 이전에는 휘발성분보다 수분이 제거됨으로써 상대적 으로 휘발성분 비율이 높아진 것으로 생각된다.

Table 3의 원소분석 결과, 황과 질소 성분의 함량 은 반탄화 온도 조건 상승과 함께 감소하는 경향을 나타내었다. 일반적으로 화석연료에 함유되어 있는 황과 질소 성분은 환경오염의 주범 중 하나로 산성비 의 원인이기도 하다.(13) 하지만 반탄화 생성물은 황 과 질소 성분의 함량이 낮아 대기환경에 미치는 영향 이 크지 않을 것으로 판단된다. 한편, 탄소는 반탄화 온도가 높아짐에 따라 그 비율이 올라가며 산소와 수 소원자의 비율은 낮아진다. 산소와 수소원자의 경우 반탄화가 진행됨에 따라 하수슬러지 탈수케이크를 이 루고 있는 수분이 가스의 형태로 배출되어 감소하는 경향을 나타내는 것으로 보여 진다. 반면 탄소 비율 의 증가는 수분 손실로 인해 상대적으로 함량이 높아 진 것으로 판단되며, 높은 수분함량으로 연료로서 사 용이 적합하지 않는 탈수케이크의 연료화 방법으로 반탄화 처리의 활용가능성을 확인할 수 있었다.

3.3 반탄화 생성물의 연료 특성 


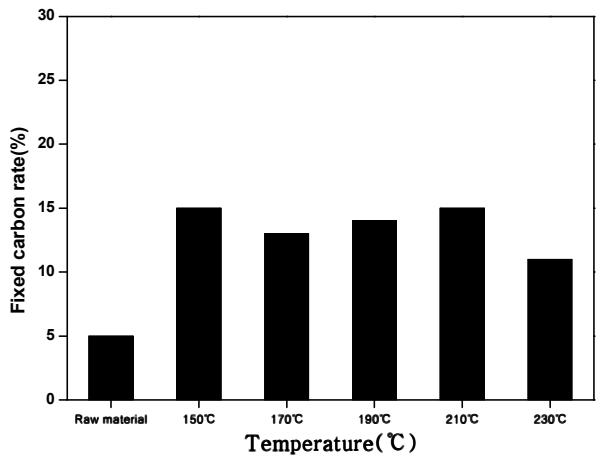

Fig. 4. Effect of temperature on fixed carbon rate in 60 minute of reaction time

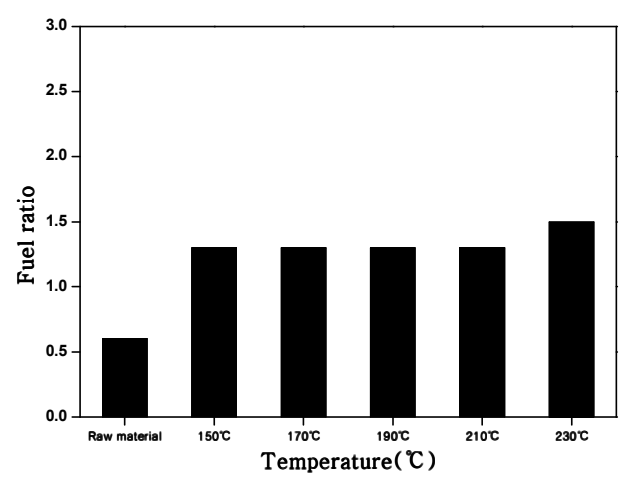

Fig. 5 Effect of temperature on fuel ratio in 60 minute of reaction time

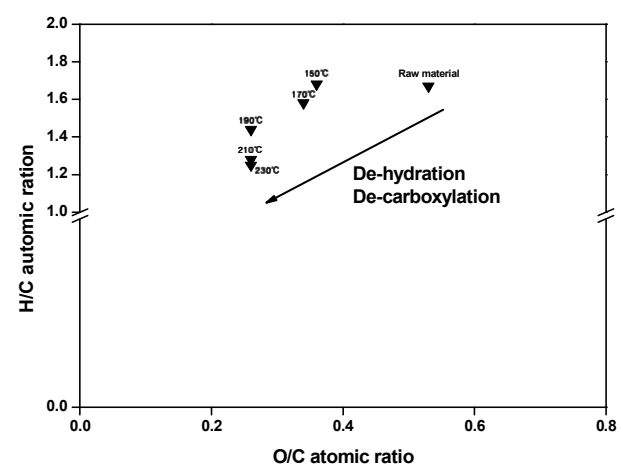

Fig. 6. Van Krevelen Diagram of torrefied products by different temperature in 60 minute of reaction time

반탄화 처리에 의한 생성물인 차(char)의 연료적 특성을 평가하기 위해 고정탄소율, 연료비, 석탄밴드 를 판단지표로 선정하였다. 이 가운데 고정탄소율은 폐기물에너지(Waste to Energy, WtE)가 매립지 수명
연장, 소각량 저감과 더불어 지구 온난화 대책의 일 환으로 진행되는 점을 고려한다면 선정이유로 의미가 있다.(14) Fig. 4에 보이는 바와 반탄화 온도가 높아 짐에 따라 하수슬러지 탈수케이크에 비해 고정탄소율 은 크게 증가하였다. 특히 반탄화 온도 $150^{\circ} \mathrm{C}$ 와 21 $0^{\circ} \mathrm{C}$ 에서 가장 높은 비율을 나타냈으며, 이는 고정탄 소수율은 반응온도에 비례하여 증가하지 않으며 반탄 화 생성물의 수율 및 회분 함량과 관련이 있는 것으 로 판단된다.

연료비는 Fig. 5 에 나타내었다. 연료비는 공업분석 결과인 고정탄소(\%)를 휘발분(\%)으로 나눈 값으로 석탄 품질 표시에 주로 사용된다. 탈수케이크의 연료 비는 0.6 으로 낮은 값을 보였으나, 반탄화가 진행됨 에 따라 $1.3-1.5$ 범위의 값을 나타내었다. 특히 낮 은 반응온도의 반탄화 처리 후에도 1.3 의 연료비를 보여주며, 일반적으로 갈탄이 1.0 이하, 역청탄이 1 4 , 무연탄이 4.0 이상의 값임을 고려한다면(반탄화 생 성물은 연료비 값만으로는 역청탄에 가까우며, 국내 석탄 발전시설에서 사용하는 석탄종이 아역청탄 $(0.5$ - 1.0)과 역청탄(1.0 -2.0)계열을 수입하여 사용하고 있기 때문에(15) 석탄과 혼소시 연료의 적합성이 판 단되면 대체 연료로서의 가능성도 충분하다고 볼 수 있다.

석탄밴드는 석탄화 과정 중 생물학적 변화와 가압 건류에 의해 탈 탄산 및 탈수작용으로 인해 낮은 값 을 보이며 그 값이 낮을수록 고등급으로 판단한다. Fig. 6는 반탄화 온도별 석탄밴드의 특성을 나타내었 다. Fig. 6에 나타난 바와 같이 반탄화가 진행될수록 석탄밴드는 개선되는 것으로 나타났다. 즉 반응온도 가 높아질수록 $\mathrm{O} / \mathrm{C}$ 와 $\mathrm{H} / \mathrm{C}$ 의 관계가 낮아지는 경향 을 보이며, 일반적으로 석탄화도가 갈탄, 아역청탄, 역청탄, 무연탄 순이며 저등급 석탄의 $\mathrm{H} / \mathrm{C}$ 범위가 0.8 - 1.3, $\mathrm{O} / \mathrm{C}$ 범위가 $0.2 \sim-0.38$ 인 점을 고려한다 면(16), 반탄화에 의해 하수슬러지 탈수케이크가 저 등급 석탄으로 연료 등급이 개선되었음을 확인 할 수 있었다.

\section{4. 결 론}

본 연구는 하수처리공정의 부산물인 하수슬러지 탈수케이크를 사용하여 반응온도와 반응시간을 달리 하여 반탄화를 진행하였고, 이로부터 반탄화 생성물 
의 특성 및 연료로서의 가능성을 알아보고자 하였으 며, 다음과 같은 결론을 얻을 수 있었다.

1) 다양한 반응온도 $\left(150,170,190,210,230{ }^{\circ} \mathrm{C}\right)$ 와 반응시간(10 - 60분)에 따른 반탄화 처리 결과, 반탄화 온도와 시간이 증가함에 따라 수분함량은 크게 감소하였고, 발열량은 증가하였다. 이는 반 탄화가 진행되면서 하수슬러지 탈수케이크가 포 함하고 있는 수분이 증발되어 가스로 발생하기 때문이며, 반응온도 $210^{\circ} \mathrm{C}$ 이상에서는 반응시간 에 관계없이 수분함량과 발열량이 유사한 경향을 보여 반탄화의 중요한 운전조건이 반응온도임을 확인할 수 있었다.

2) 반응시간을 60 분으로 고정하고, 반응온도 조건에 따른 반탄화 생성물 차(char)의 공업분석 및 원소 분석 결과, 온도조건이 상승함에 따라 수분함량은 감소하고 고정탄소는 증가하였다. 고정탄소 함량 의 증가는 발열량 상승과 연관이 있으며, 산소와 수소 함량의 감소는 수분 증발에 의한 것이며, 이 로 인하여 상대적으로 탄소의 함량은 증가하는 것으로 보여 진다. 특히 반탄화 반응에 의한 황과 질소 함량 감소는 반탄화 생성물이 친환경연료로 서 가능성을 가지고 있음을 보여 주었다.

3) 반탄화 온도 조건의 향상에 따른 반탄화 생성물 차(char)의 연료적 특성을 평가한 결과, 발열량의 주체인 고정탄소의 수율은 높아지고, 연료비는 낮 은 반응온도에서도 역청탄에 가까운 값을 나타내 었다. 즉 하수슬러지 탈수케이는 수분함량 감소만 으로도 연료 등급이 개선되는 것을 확인할 수 있 었으며, 석탄밴드를 통해 반탄화 생성물의 석탄화 도가 개선되어 저등급 석탄으로 석탄화가 진행된 것을 알 수 있었다. 이는 일반 석탄에 비해 하수 슬러지의 탈수케이크는 높은 산소 함량을 나타내 며, 반탄화 처리를 통해 이 산소와 수소가 함께 제거되면서 수분 감소와 더불어 고정탄소 증가로 에너지 밀도가 증가하여 높은 발열량을 나타내는 것으로 판단된다.

향후 보다 더 다양한 조건에서의 반탄화 실험을 할 필요가 있으며, 에너지원으로의 가치 평가를 위해선 물질 수율 및 에너지 수율, 반탄화 생성물의 연소 특 성 등 추가적인 연구가 필요할 것으로 사료된다.

\section{감 사}

이 논문은 2013년도 SL공사의 환경에너지대학원 인재양성 프로그램에서 지원받아 수행된 연구입니다.

\section{참고문헌}

1. 남원준 외 : 발전용 석탄과 하수슬러지 고형연 료탄의 혼소시료 특성 연구, 한국폐기물학회, 춘계학술연구회 발표논문집, 304-307, (2010).

2. 정성배 : 하수슬러지의 탄화에 관한 실험적 연구, 박사학위논문, 원광대학교, 2-3, (2011).

3. 김기석 외 : 반탄화 우드칩의 열분해 특성 및 발 열량에 관한 연구, 한국화학공학회, 추계학술연 구회 발표 논문집, vol. 23, (2012).

4. 박영수 외 : $\mathrm{EFB}($ Empty Fruit Bunch) 반탄화 시 생성된 Char의 수율 및 특성에 대한 운전변수 의 영향, 한국폐기물학회, 추계학술연구회 발표 논문집, vol 29, (2012)

5. 박상우 외 : 기계적으로 선별한 가연성폐기물의 탄화 ; 생성물의 연료특성 조사, 한국폐기물학 회, 춘계학술연구회 발표 논문집, vol 30 , (2013)

6. 배재근 외 : 유기성폐기물의 자원화 기술의 현황 과 전망, 대한위생학회, 3-20, (2001)

7. Fenfen $\mathrm{Zhu}$ 외: The study of sewage sludge Thermo-Drying Efficiency, ICWNT7, vol 16, (2012)

8. M.J.C. van der Stelt 외 : Biomass upgrading by torrefaction for the production of biofuel: A review, The Netherlands, (2011)

9. J.J Chew, V. Doshi 외 : Recent advances in biomass pretreatment \&\#8211; Torrefaction fundamentals and technology, Malaysia , (2010)

10. 이재원 외 : 고에너지밀도 펠릿제조를 위한 목 재칩 반탄화 특성, 한국화학공학회, 춘계학술연 구회 발표 논문집, vol 50, (2012)

11. 박상우 외 : 탄화에 의한 하수슬러지의 연료개 질 특성, 한국폐기물자원순환학회, vol 27, 674-680, (2010)

12. 이명석 외 : Oil Palm Frond의 반탄화를 통한 연료화 연구, 한국화학공학회, 465-469, (2013) 
13. 서명원 외 : 바이오매스 가스화 정제 기술 소개 및 현황, KIC, vol 15, (2012)

14. 이동영 외 : 국산 붉가시나무 탄화물 분석, 한국 목재공학 학술 발표 논문집, 213-214, (2012)

15. 이재근 : 석탄 화력발전소에서 발생되는 석탄회 의 수분함유량 및 온도에 따른 비저항성 특성 연구, 대한기계학회논문집, 526-532, (2000)

16. 최우진 외 : 석탄의 고품위화를 위한 선별성 향 상에 관한 연구, 한국지구시스템공학회지, 293-299, (1993) 